\title{
An Analysis of Funding for the NSF REU Site Program in Biology from 1987 to 2014
}

Christopher C. Barney, Hope College

\begin{abstract}
Using data available at the NSF Search Awards site, Biology REU Site awards made from 1987 to 2014 were analyzed. During this time, there was an average of 30.8 new REU Site awards per year with an average duration of three years. Total funding for Biology REU Site awards increased for each four-year period analyzed since 19951998 in actual dollars but has not increased substantially in inflation-adjusted dollars since 2003-2006. Average award funding in inflation-adjusted dollars increased from 19871990 to 2003-2006, which reflects the increased duration of awards, and then declined slightly for the 2007-2010 and 2011-2014 periods. Awards have been made to institutions in every state except Wyoming as well as to institutions in Washington, DC, and Puerto Rico. The total Biology REU Site funding per state/location is highly correlated with the state/location population. Awards have been made to 257 institutions and to 480 principal investigators (PIs). Many institutions (33.8 percent) and PIs (56.7 percent) have had only one Biology REU Site award, whereas 10.5 percent of the institutions and 0.4 percent of the PIs have had eight or more awards. Doctoral institutions had the largest percentage of awards (65.5 percent), followed by research institutes, master's institutions, bachelor's institutions, medical institutions, associate's institutions, and tribal colleges. From the 1987-1990 to the 2011-2014 analysis periods, the percentage of awards made to master's institutions increased from 9.6 percent to 15.3 percent, and the percentage of awards made to bachelor's institutions decreased from 13.3 percent to 2.1 percent.
\end{abstract}

Keywords: biology, funding, REU Sites, National Science Foundation

doi: 10.18833/spur/1/1/1

\section{Introduction}

In 1987, the National Science Foundation (NSF) initiated the Research Experiences for Undergraduates program (REU) (http://www.nsf.gov/funding/pgm_summ.jsp?pims_ $\mathrm{id}=5517 \&$ from=fund). The REU program offers primarily two types of awards. REU Supplements provide funds to NSF research award recipients to support one or two undergraduate students working on their research projects. REU Sites provide funds for 6 to 12 students working with usually more than one scientist on research projects related to a common theme. REU Site awards have some similarities to the earlier awards for the NSF Undergraduate Research Participation program (URP), although the URP program did not usually require the recruitment of students from outside of the institution (Doyle 1987). The URP program ran from 1959 until 1981, when it was terminated despite calls for its continuation (Doyle 1987; Neckers 1982). The author participated in an NSF URP program in biology at Wright State University in summer 1972 and directed an NSF REU Site program at Hope College for several years. Although the Hope College Biology Department had REU support for 24 years, the department has been unsuccessful in obtaining further funding. Such developments led to an analysis of NSF Biology REU Site funding data to determine if there were any trends in funding that might relate to the department's grant success rate. In addition to discovering other interesting data, it was found that the percentage of Biology REU Site grants awarded to institutions that award primarily bachelor's degrees has declined considerably since the first few years of the program. This article analyzes NSF Biology REU Site program funding from 1987 to 2014 in terms of numbers of awards; award and program funding levels; and distribution of awards by location, institution, principal investigator (PI), and type of institution. 
The impacts of undergraduate research in science, technology, engineering, and math (STEM) fields on the research participants have been studied extensively in the last 25 years, and many positive effects of research participation have been documented. Lopatto $(2004,2007,2009)$ reported that participation in undergraduate research led to gains in areas such as understanding the process of research and ways in which scientists work, learning lab techniques and methods of working independently, analyzing data and interpreting results, integrating theory and practice, clarifying the career path, and building self-confidence. There were no clear differences in these gains among students who performed research at colleges, master's-level institutions, or research institutions, but the quality of mentoring was important in the satisfaction level of the undergraduate participants. Using interviews of research students rather than surveys, Seymour and colleagues (2004) found similar outcomes with positive benefits noted in areas such as improving research and communication skills, working and thinking like a scientist, clarifying the career path, and preparing for graduate school. The Undergraduate Research Student Self-Assessment instrument now in use to assess REU Sites provided data showing that students who participated in undergraduate research had self-reported gains in research skills, career clarification and preparation, and the process of working and thinking like a scientist (Hunter et al. 2009).

Thiry and colleagues (2013) reported that, as time spent doing research increased, generalized problem-solving, understanding how to collect data, analyzing data for patterns, and building personal confidence in the ability to do research also increased. Schmitz and Havholm (2015) reported on the results of a survey of their institution's alumni who had participated in undergraduate research. The alumni reported that undergraduate research led to gains in higher-order thinking skills and personal development as well as gains in discipline-specific areas. Comments made about their research experiences by the survey respondents were very positive and included praise for faculty mentoring as well as preparing for graduate school and careers.

Participation in undergraduate research has also been shown to affect career choice and satisfaction. Lopatto (2007) found that undergraduate research either increased or maintained students' interest in advanced study in a STEM field or medicine with 45 percent of the survey respondents indicating a plan to obtain a $\mathrm{PhD}$ in a STEM field. Yaffe and colleagues (2014) reported that a survey of participants in the Undergraduate Biology Research Program at the University of Arizona from 1988 to 2010 showed that 45 percent had obtained or were in the process of obtaining a $\mathrm{PhD}$ degree, and 7 percent had obtained or were obtaining both the MD and $\mathrm{PhD}$ degrees. In addition, they found that presenting or publishing the research results and interactions with a mentor were identified as influences on career path by 24 percent and 35 percent of the respondents respectively, whereas 81 percent of the respondents indicated personal interest as an influence. Eagan and colleagues (2013) reported that undergraduate research participation significantly increases the intent of students to pursue graduate school in some STEM field.

There have also been studies on how students select REU programs and the impact of the NSF REU program in general. A recent paper by Economy and colleagues (2014) provides both a review of history of the REU program and an analysis of factors used by students in making decisions about applying for and participating in a REU program. The primary factors were the focus of the particular project, the level of the stipend, the date of the offer, and the housing and meal plan offered. They also reported that most applicants applied to four or more programs.

The first three years of the REU program were evaluated by Fitzsimmons, and the results were summarized in a report from NSF (1990). At that time, 10 percent of the participants had finished only one or two years of college, 43 percent were female, 10 percent belonged to minority groups underrepresented in STEM fields, and 59 percent were from predominantly undergraduate institutions. They also reported that participation increased plans to seek a $\mathrm{PhD}$ The results of a later study on NSF's support for undergraduate research were reported by Russell (2006) and summarized in Science (Russell et al. 2007). They reported that women composed 53 percent of the NSF-supported undergraduates, 27 percent of the participants belonged to minority groups underrepresented in STEM fields, and first- and second-year students still made up a small percentage of the total participants. These investigators found that 68 percent of the undergraduates who participated in research with support from NSF reported an increased interest in a STEM career, and 29 percent reported an expectation of obtaining a $\mathrm{PhD}$ that did not exist prior to research participation. In addition, undergraduate research increased awareness of expectations at the graduate school level, increased confidence in research skills, and increased understanding of how to do research. Increasing enthusiasm of students for research was seen as a major effect of an undergraduate research experience, and involving more students who had finished only one or two years of college was a recommendation that emerged from the study.

Beninson and colleagues (2011) reported on the results of a four-year survey of Biology REU Site directors that was updated by O'Connor (2014). They reported that, from 2006 to 2013, the number of applications to Biology REU Sites doubled, whereas the success rate for applications decreased from 7.8 percent to 4.3 percent, that the percentage of participants from external institutions ranged from 82 percent to 90 percent, that about 63 percent of the participants have been female and about 47 percent have 
belonged to minority groups underrepresented in STEM fields, and that more than 50 percent of the participants had just completed their junior year. Benison and colleagues (2011) also reported that most REU Sites include workshops, seminars, research presentations, and social events as part of the REU Site activities. The measurements of program success by the PIs included matriculation at graduate school, presentation or publication of results, and general satisfaction with the program. Further, it was suggested that individuals seeking REU Site funding consider NSF's goals of increasing the number and diversity of the students who apply for positions and the benefits of including younger students in a program, as well as involving the students in cutting-edge research.

These reports provide important information about the REU Site Program in Biology and demonstrated that the NSF REU and other NSF undergraduate research support programs were accomplishing the goals of providing undergraduates with intensive research experiences, increasing the diversity of undergraduate students participating in research, increasing interest in STEM careers, and increasing the numbers of students who had earned or who expected to earn a PhD in a STEM field. In the spirit of these reports, the following details regarding the history of funding of NSF Biology REU Sites are offered.

\section{Funding for the NSF Biology REU Site Program, 1987-2014}

\section{Methods}

To obtain information about NSF Biology REU Site funding, NSF Search Awards site (http://www.nsf.gov/ awardsearch/) was accessed on October 12, 2015, and two searches were conducted:

- A search for active and expired awards under NSF Organization DBI BIO (Directorate for Biological Sciences) and Program Code $=9250$, Research Experiences for Undergraduate Sites, from 1/1/1987 to 12/31/2014.

- A search for active and expired awards under NSF Organization DBI BIO and Keyword=REU from 1/1/1987 to $12 / 31 / 2014$.

The results were downloaded, the files were combined, and duplicate awards were eliminated. Using the award titles and abstracts, awards with REU in the title that had been made through the Division of Environmental Biology were eliminated, as these were not Research Experiences for Undergraduates awards, and other awards that included REU in the abstract but were not Biology REU Site awards were also eliminated.

REU awards that were made for funding an activity other than a REU Site were then eliminated. Omitted were five awards to support workshops for Biology REU Site directors (in 2003, 2007, 2010, 2012, and 2014 for a total of $\$ 352,412$ ), three awards to evaluate site programs (all in
2010 for a total of $\$ 144,617$ ), one to review and develop modules on ethics in research (in 2011 for $\$ 97,461$ ), three to support travel of REU students to meetings and miscellaneous support (in 2010, 2012, and 2013 for a total of $\$ 317,996)$, and two to develop a common tracking tool and a long-term outcomes assessment (both in 2012 for a total of $\$ 41,234)$. This left 863 awards for analysis. Analysis was primarily carried out using the PivotTable function of Excel. It is important to note one major limitation of this study is the completeness and accuracy of the data obtained from searching for Biology REU Site awards using the NSF Search Awards system. For several figures, the data were divided into seven four-year intervals covering the period 1987-2014.

\section{Number of New Awards}

Figure 1A shows the number of new Biology REU awards during each four-year period. Award numbers have been fairly steady except for the periods 1995-1998 and 1999-2002, when award numbers were 59 percent and 81 percent of the average number of awards for the other periods. The number of awards may reflect both funding levels for the Biology REU program at NSF and the duration of awards. There was a small decline in the overall NSF budget during 1996-1998, with $\$ 3.56$ billion budgeted in 1995 and with an average of $\$ 3.50$ billion per year from 1996 to 1999 (AAAS 2016). As seen in Figure 2B, average award duration increased substantially during the second and third periods. As NSF committed more funding to continue REU Sites for longer periods of time, less funding was available to support new proposals.

\section{Total Funds Awarded}

Figure 1B shows the total funds awarded for the four-year periods in both actual and inflation-adjusted amounts. The inflation-adjusted amounts were determined using 1987 as the baseline and multiplying the actual amounts by the Consumer Price Index impact for each year (U.S. Department of Labor 2016). Actual award dollars for Biology REU Site awards increased for each four-year period except for 1995-1998, when there was an 8 percent decrease from the previous four-year period. Inflationadjusted award dollars increased by 62 percent from 1995 1998 to $1999-2002$ and by 57 percent from 1999-2002 to 2003-2006 but have remained steady at approximately $\$ 21.6$ million per period since then. Thus, the NSF Biology REU site program has shown no real growth in the last 8-10 years, which should be of concern to those involved in training the next generation of biology research scientists and others for the STEM workforce.

Figure 1C shows the average funds per award for the four-year periods in both actual and inflation-adjusted amounts. The actual average award dollars increased for every year of the program from approximately $\$ 50,000$ per award in 1987-1990 to approximately $\$ 315,000$ per award 
FIGURE 1. Numbers and Funding Levels of Biology REU Site Awards, 1987-2014

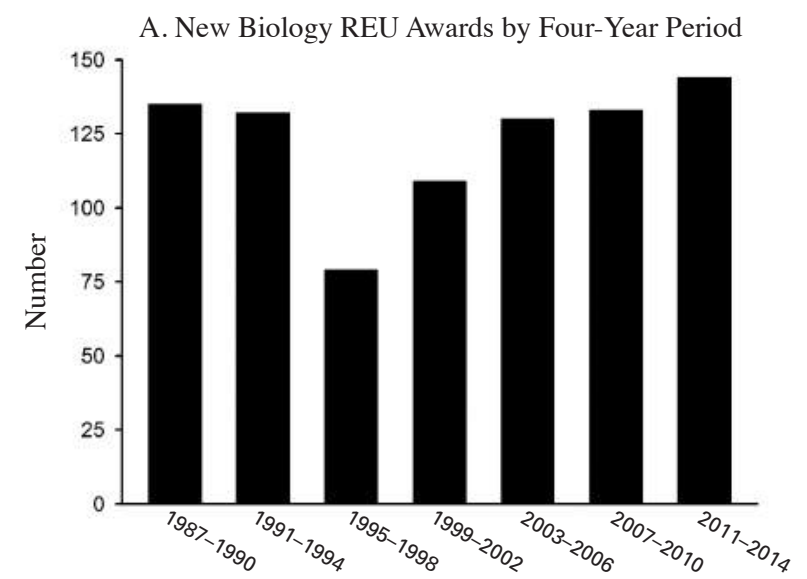

Four-Year Period

B. Total Biology REU Award Amounts by Four-Year Period

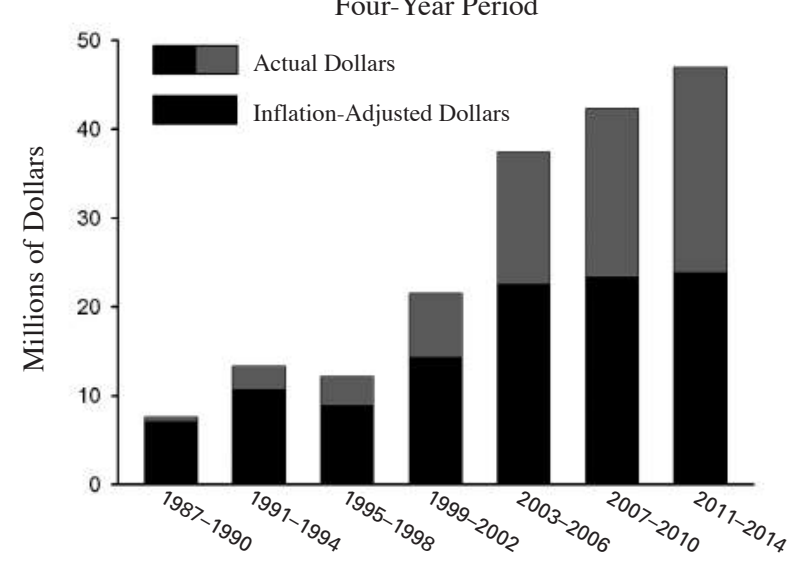

Four-Year Period

C. Average Biology REU Award Amounts by Four-Year Period

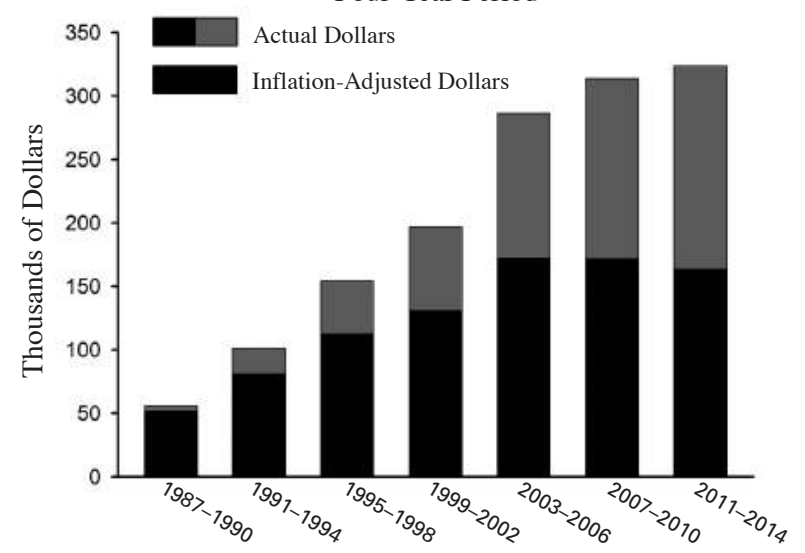

Four-Year Period

in 2011-2014. In inflation-adjusted dollars, the average award increased for the first five periods but then declined slightly for the last two periods. In inflation-adjusted dollars, the average award was approximately $\$ 46,000$ in

14 Scholarship and Practice of Undergraduate Research
FIGURE 2. Durations of Biology REU Site Awards, 1987-2014

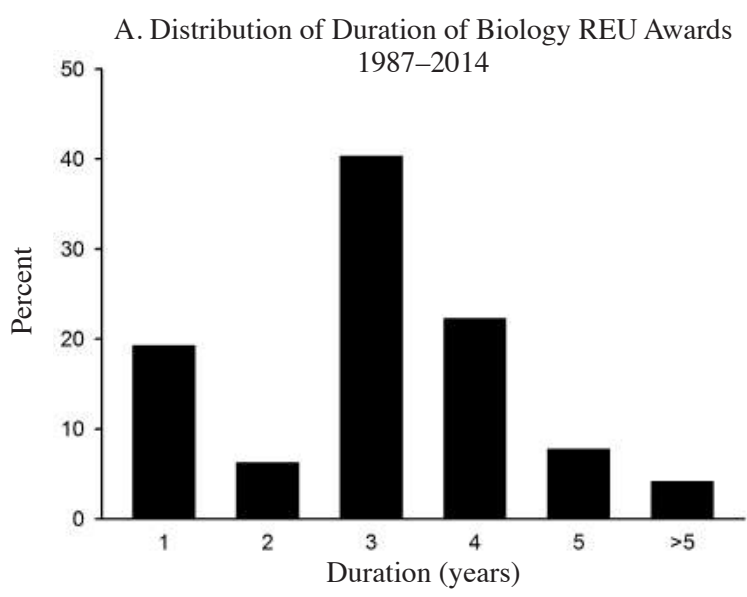

B. Average Duration of Biology REU Awards by

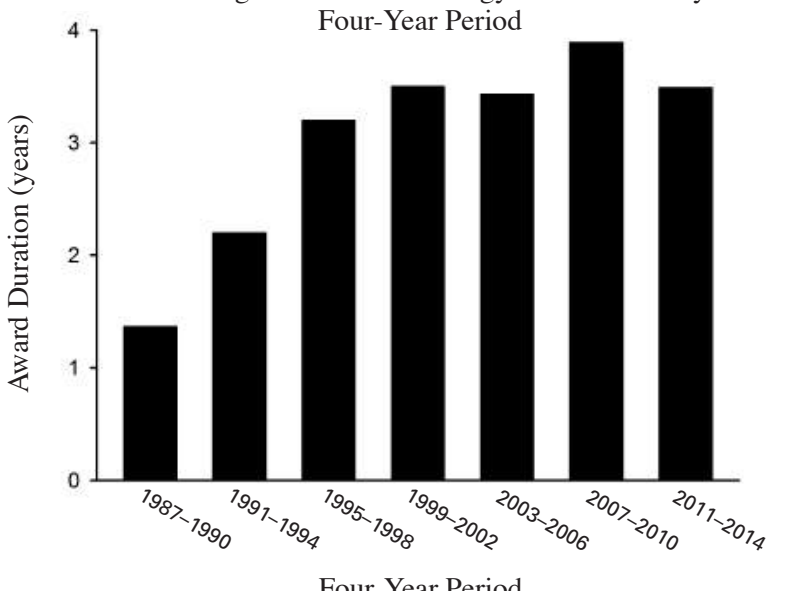

C. Duration of Biology REU Awards by Four-Year Period

$$
\begin{array}{ll} 
& 1 \text { Year } \\
2 \text { Years } & \text { Years } \\
& 2 \text { Years } \\
& \text { Years } \\
&
\end{array}
$$

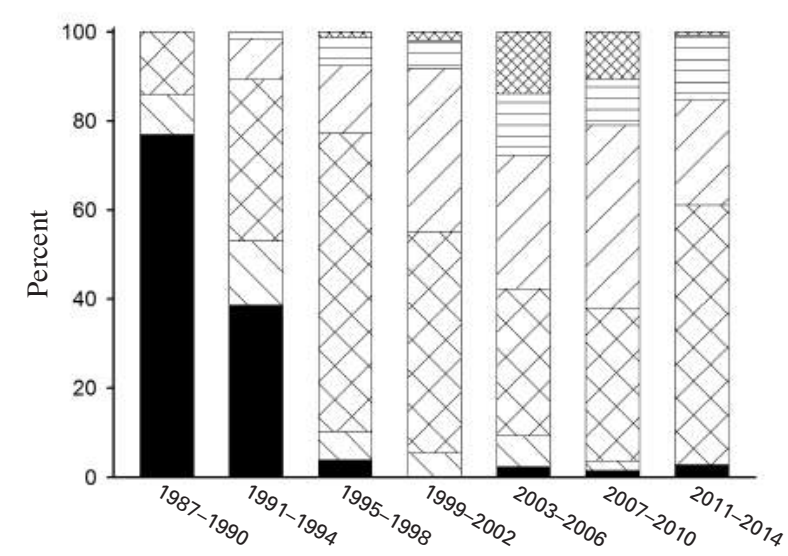

Four-Year Period

1987-1990 and approximately $\$ 155,000$ in 2011-2014. These increases reflect both the increased average duration of awards and the increased amount suggested per year per student in the NSF REU program solicitations. 


\section{Award Durations}

Figure 2 provides data on the duration of awards. Award duration was determined by subtracting the award start dates from the award stop dates, dividing the resulting days by 365 to give years and then rounding the data into whole years with 0.50 values being rounded down. This was done to take into account the extra part of a year added by NSF to award duration primarily for reporting purposes. Award duration was also affected by programs that requested and received extensions of awards, so the reported durations may be greater than actual years of student support. The average duration of Biology REU Site awards from 1987 to 2014 was 3.06 years. Almost 75 percent of the awards were for three or more years (see Figure 2A). The average award duration increased from 1987-1990 to 1999-2002 and then leveled off with a small increase during 2007-2010. The distributions of durations of REU awards for each of the seven time periods are shown in Figure 2C. Whereas one-year awards were predominant from 1987-1990 when both the national REU program and individual sites were new, one-year awards declined to just a small percentage of the awards by $1995-1998$. As the REU program matured, three- and four-year awards became the norm with relatively few awards lasting longer than four years. The distribution of durations of awards most likely reflects proposal requests and prior results, and may also reflect the balance attempted by NSF between providing stability in institutional REU Site programs and funding as many sites as possible. Multiplying the number of awards by the average duration of the award and by an estimate of the number of students supported each year by an award (10) gives an estimate of approximately 26,000 students supported by Biology REU Site awards.

\section{Award Locations}

Biology REU Site awards have been made to institutions in every state except for Wyoming and to institutions in Washington, DC, and Puerto Rico. Figure 3A shows how the number of awards has varied by location. More than half of the locations (32) have received 15 or fewer awards, and three locations have received more than 60 awards, with 15 locations receiving between 16 and 20 awards. Thus the identification of worthy Biology REU Site proposals throughout the country seems to have been achieved. Figure 4 shows the award distribution by location (Puerto Rico had seven awards). Award numbers were lowest in the Northwest, as well as parts of the South and New England. California, Massachusetts, and New York each had more than 60 awards.

Figure 3B shows a regression analysis of the total funding between 1987 and 2014 by location versus location population as determined by the 2000 census (about halfway between 1987 and 2014; U.S. Bureau of the Census $2000)$. There is a highly significant $(p<0.001)$ relationship between population and total funding. Data points for
FIGURE 3. Biology REU Site Awards by Location, 1987-2014

A. Distribution of Number of Biology REU Awards by State (Including Washington, DC, and Puerto Rico)

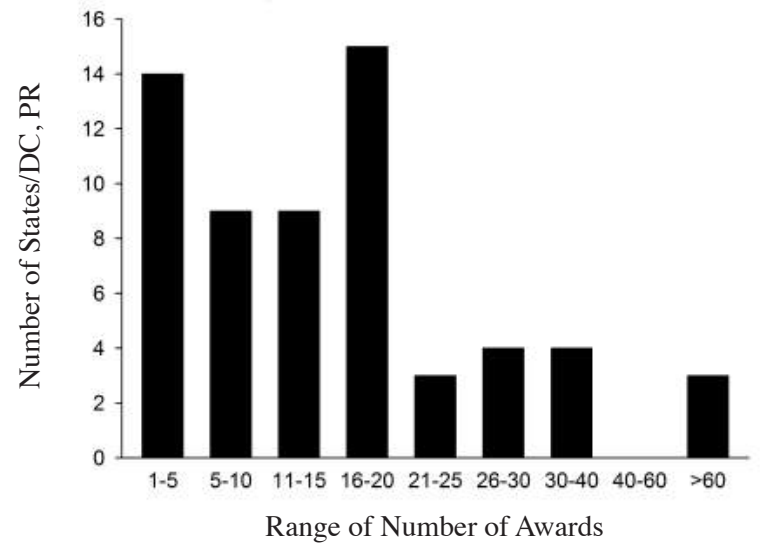

B. Total Biology REU Funding by State-vs.-State Population (Including Washington, DC, and Puerto Rico)

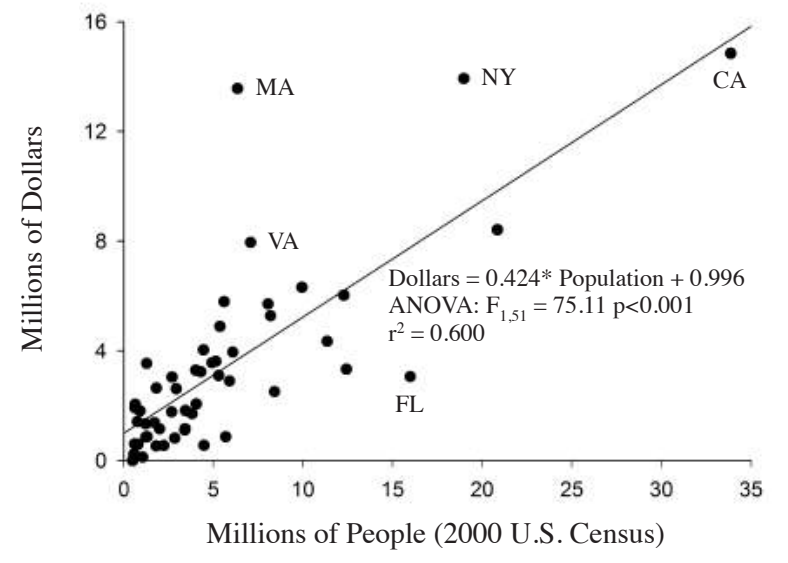

FIGURE 4. Distribution of Biology REU Site Awards, 1987-2014

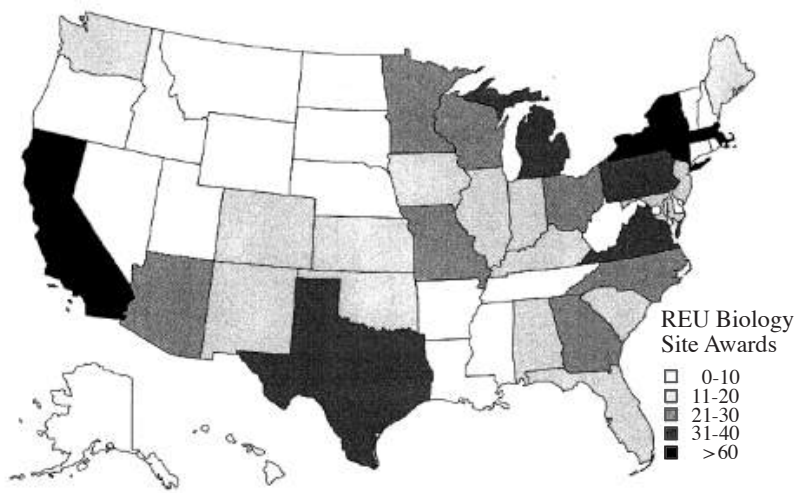

California and four outlier states (Florida, Massachusetts, New York, and Virginia) are identified. The reasons for the outlier status of these four states are not entirely clear but no doubt reflect differences in proposal submission rates. Florida has the highest percentage of the population aged 65 or older, which may account partly for its lower level 
of Biology REU Site funding than would be predicted by its population. Massachusetts is the home of Harvard University, which had more Biology REU Site funding than any other institution (more than twice as much as the institutions ranked 15th and below in funding) and home of two other institutions in the top 10 percent of funding. New York is the home of numerous research institutes, and four of these were in the top 14 percent of funding with the Carey Institute of Ecosystem Studies present in the top 5 percent of funding. Virginia is the state of record of two institutions that were in the top 3 percent of funding, with one identified as the Smithsonian Institution.

\section{Award Numbers by Institutions and Principal Investigators}

Figure 5 shows the distributions of numbers of institutions (Figure 5A) and the numbers of PIs (Figure 5B) by total number of Biology REU Site awards held. Between 1987 and 2014, Biology REU Site awards were made to 257 different institutions. Of those, 87 institutions or 33.8 percent had only a single award (Figure 5A). Seventeen of the 87 institutions with a single award currently hold their first award, which means that 70 institutions either failed to reapply for a second award or failed to receive a second award after applying. The number of institutions in each category and the reasons for either of those two possibilities would be interesting to ascertain. Of the 257 institutions, 71 percent had three or fewer awards, and only 9 percent had nine or more awards. Because at least 10 percent of the institutions have had awards for different programs, relatively few institutions have been interested in maintaining or have been able to maintain a Biology REU Site program for very long. On the other hand, this means that more institutions have been awarded REU Site funds and have had a chance to carry out a program.

Some of the data were also analyzed based on the types of institutions receiving awards. For colleges and universities, the Carnegie Classification of Institutions of Higher Education at About Carnegie Classification (Indiana University 2015) was used, and then the institutions were clustered into six broad types (Carnegie Classifications): associate's (Assoc/Pub4), tribal (Tribal), bachelor's (Bac/A\&S, Bac/Assoc, and Bac/Diverse), master's (Master's S, Master's M, and Master's L), medical (Spec/ Med), and doctoral (DRU, RU/H, and RU/VH). One newer institution had not yet been categorized, but, based on the description of the institution at its website, it was categorized as a doctoral institution. Biology REU awards have also been made to non-academic institutions such as research institutes and government entities, and these were clustered together as research institutes. The number of awards per institution (Figure 5A) differed among the different types of institutions with only doctoral institutions and research institutes receiving more than six awards (with one exception).
FIGURE 5. Distribution of Number of Biology REU Site Awards by Institution and Principal Investigator, 1987-2014
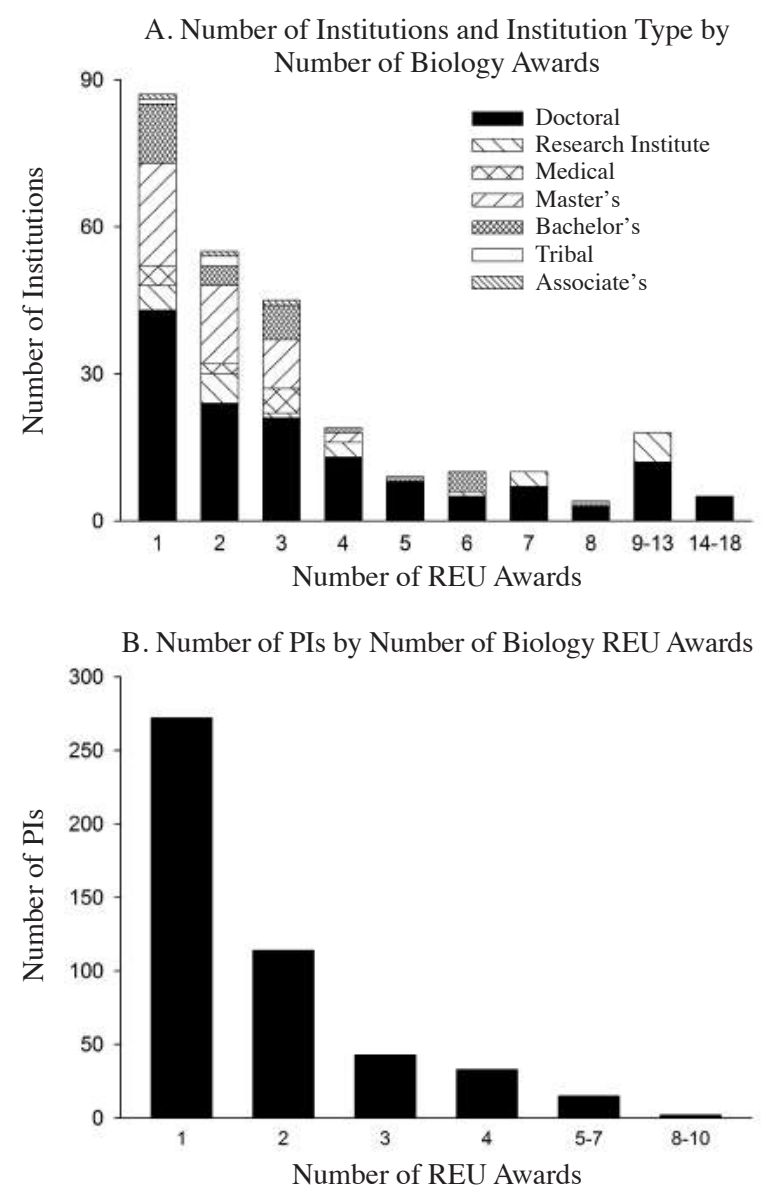

There have been 480 different principal investigators (PIs) for the 863 Biology REU Site awards. Of these, 56.7 percent have received a single award (Figure 4B), and only 3.5 percent have received more than four awards. Thus, for many PIs, obtaining REU Site funding is a one-shot deal. Assuming there were no name duplications, 19 PIs have had awards at two or more institutions, including one PI who had awards at five different institutions. This demonstrates that some PIs have the ability to transfer their expertise in running a REU Site program to other institutions.

Of the 257 institutions with REU Site awards, 103 (40 percent) have had more than one PI for their awards. Thus there are a greater number of PIs than institutions receiving awards, which can be attributed to several causes. Some institutions have multiple REU programs, sometimes running concurrently. In some cases, the administration of an institution may select a new person to write and submit the proposal and direct the program, perhaps because the prior PI, who might be a staff person working as a director of undergraduate research, has left the position or institution. In many cases, however, it is also likely that the PI decided not to continue in that role. One factor 
in that decision may be a general lack of institutional reward for faculty in obtaining REU Site Award funding and directing the program. At many institutions, including Hope College, the award of funding for an REU Site does not carry with it the prestige and rewards (in terms of summer salary or merit raises) as does an NSF or NIH funding award for research. In most cases, the joys of interacting with outstanding undergraduates and the satisfaction of contributing to increasing the number and diversity of students who enter the STEM workforce are the primary rewards for the PI.

\section{Award Type of Institution}

From 1987 to 2014, a majority (65.5 percent) of the REU Site awards were made to doctoral institutions (Figure 6A). In descending order by percentage, awards were made to research institutes, master's institutions, bachelor's institutions, medical institutions, associate's institutions, and tribal colleges (Figure 6A). It would be of interest to learn from NSF if the difference in award numbers among types of institutions is a reflection of differences in numbers of proposals submitted, success rates of proposals, or both. The data for the total award amounts by institution type are shown in Figure $6 \mathrm{~B}$ and are very similar to the data for percentage of awards for the various institution types, with the exception of the bachelor's institutions, which received 7.2 percent of the awards but only 5 percent of the funding. Figure $6 \mathrm{C}$ gives the average amount of funding per award for the seven different types of institutions. The higher levels for tribal colleges and associate's institutions may be attributable to inflation, as these institutions did not receive any awards during the first eight years of the program. Of the other types of institutions, research institutes had the highest average award amount at $\$ 229,000$, and bachelor's institutions had the lowest award amounts at $\$ 138,000$. These differences can be attributed to both differences in the average award duration (3.31 years for research institutes and 2.58 years for bachelor's institutions) and perhaps to smaller yearly numbers of REU students at bachelor's institutions.

The way in which the distribution of awards to different types of institutions changed over the first 28 years of the NSF Biology REU program was also determined. As shown in Figure 7 , the percentage of awards made to doctoral institutions has remained fairly steady when analyzed by four-year periods, with percentages varying from 63.3 percent to 67.2 percent. Medical institutions averaged 4.9 percent of the awards from 1987-2002, but only 1 percent of the awards from 2003-2014. No awards were made to associate's institutions during three of the seven periods, and the percentage averaged 1.4 percent during the other four periods. Tribal colleges only received awards during the last three periods, averaging 1.2 percent of the awards during those times. These awards reflect, in part, the efforts of NSF to encourage proposals from both
FIGURE 6. Distribution of Biology REU Site Awards by Institution Type, 1987-2014

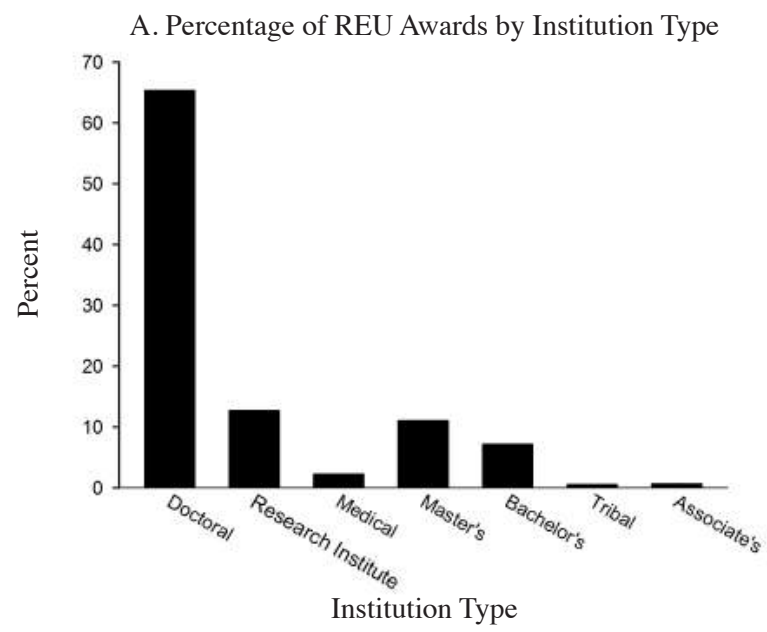

B. REU Awards Total Amounts by Institution Type

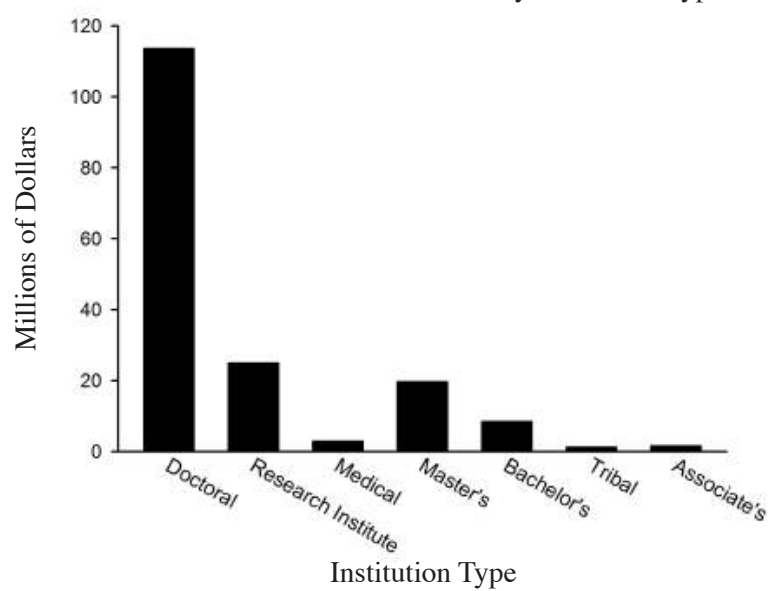

C. REU Awards Average Amounts by Institution Type

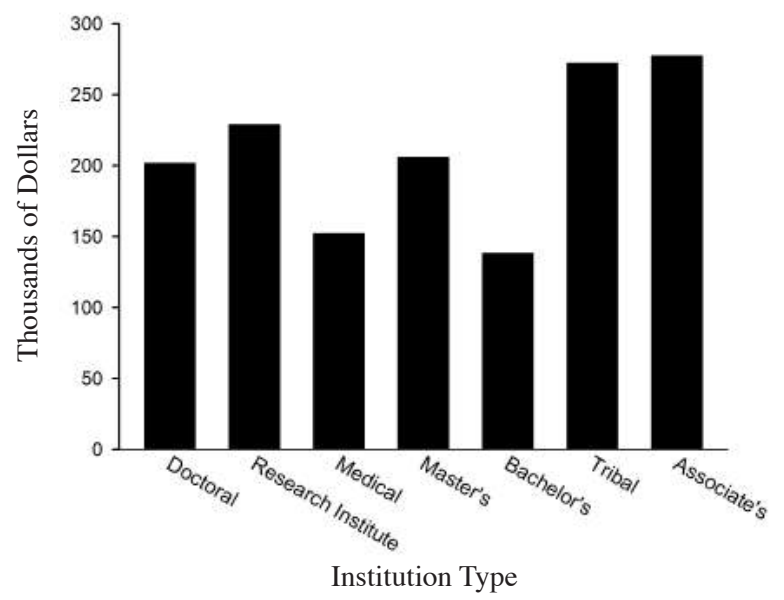

associate's institutions and tribal colleges. The percentage of awards made to research institutes has varied from 9 percent to 17.7 percent during the four-year periods averaging 12.7 percent of all awards. During the first four years of the Biology REU program, 9.6 percent of the awards were made to master's institutions. This declined 
FIGURE 7. Changes with Time in the Distribution of Biology REU Site Awards by Institution Type, 1987-2014

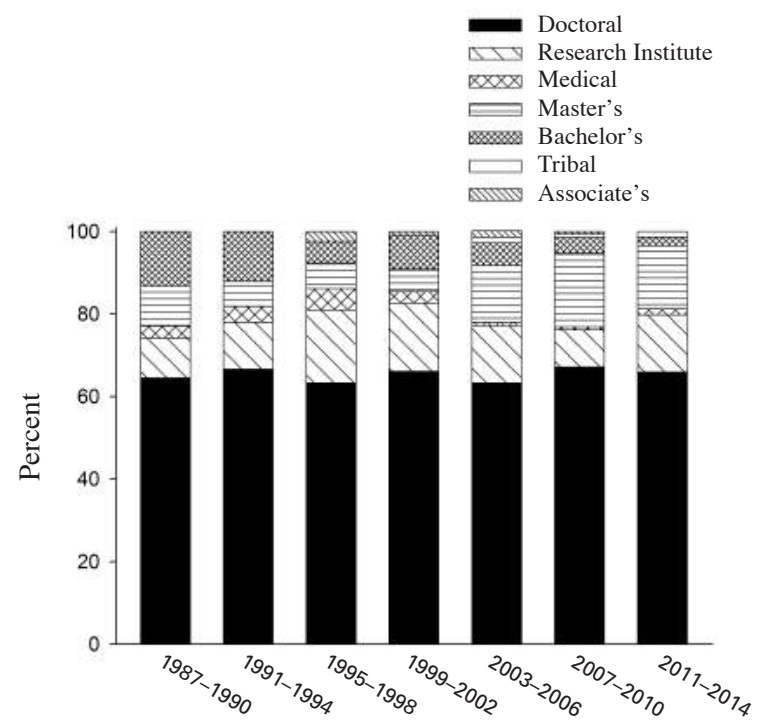

Four-Year Period

to an average of 6 percent of the awards from 1991-2002 but then more than rebounded such that master's institutions received an average of 15.7 percent of the awards from 2003-2014.

The institutional group that has shown the largest, fairly steady decline in the percentage of awards obtained is the bachelor's institutions. During the first four years of the program, bachelor's institutions received 13.3 percent of the awards, but from 2011 to 2014, they only received 2.1 percent of the awards. It is not entirely clear why the overall award percentage to bachelor's institutions has declined so much. One hypothesis is that, at some point, increased percentages of proposals from bachelor's institutions were not awarded funds and this led to general discouragement and a reduction in the number of proposals submitted from bachelor's institutions. Information from NSF about the number of proposals and the success rate of proposals from bachelor's institutions specifically and/or a survey of past and present PIs at bachelor's institutions would be of interest in this regard. It would also be of interest to determine if there has been a change in philosophy regarding the Biology REU site program at NSF or by the REU Site grant proposal reviewers. Alternatively, it is possible that PIs at bachelor's institutions have turned to other NSF grant programs to support undergraduate research, although a search of the NSF grant website for research awards to undergraduate institutions indicated that the number of such awards has been relatively stable from 1987 to 2014 . Another possibility is that PIs at bachelor's institutions have decided that the requirement for a high percentage of REU participants to come from outside their institutions has made the program less attractive to faculty participants and the institutions.

\section{Summary and Conclusions}

Since 1987, the National Science Foundation has supported the involvement of thousands of undergraduate students in research in biology through Biology REU Site awards. From 1987 to 2014, there was an average of 30.8 new REU Site awards per year with an average duration of three years. Total funding for Biology REU Site awards has increased for each four-year period analyzed since 1995-1998 in actual dollars but not increased substantially in inflation-adjusted dollars since the 2003-2006 analysis period. Average award funding in inflation-adjusted dollars increased from 1987-1990 to 2003-2006, which reflects the increased duration awards, and then declined slightly for the 2007-2010 and 2011-2013 periods. Awards have been made to institutions in every state except Wyoming as well as to institutions in Washington, DC, and Puerto Rico. The total Biology REU Site funding per state/location is highly correlated with the state/location population, with the exceptions of Virginia, Massachusetts, and New York, which had higher than predicted funding levels, and Florida, which had a lower than predicted funding level. Awards have been made to 257 institutions and 480 PIs. Many institutions (33.8 percent) and PIs (56.7 percent) have had only one Biology REU Site award, and 10.5 percent of the institutions and 3.5 percent of the PIs have had five or more awards. Doctoral institutions have had the largest percentage of awards (65.5 percent) followed by research institutes, master's institutions, bachelor's institutions, medical institutions, associate's institutions, and tribal colleges. From 1987-1990 to 2011-2014, the percentage of the awards made to master's institutions increased from 9.6 percent to 15.3 percent, and the percentage of awards made to bachelor's institutions decreased from 13.3 percent to 2.1 percent.

\section{Acknowledgments}

The author thanks Jacqueline DeBoard for assisting with the data analysis and Leah Chase for reviewing this article and providing valuable advice.

\section{References}

American Association for the Advancement of Science (AAAS). 2016. "Historical Trends in Federal R\&D." Accessed August 1, 2016. http://www.aaas.org/page/historical-trends-federal-rd.

Beninson, Lida A., Jessica Koski, Erika Villa, Ronnie Faram, and Sally E. O'Connor. 2011. "Evaluation of the Research Experiences for Undergraduates (REU) Sites Program." CUR Quarterly 32(1): 43-48.

Doyle, Michael P. 1987. "Editorial Comments: The New NSFREU Program Is Not the Return of the URP Program." CUR Newsletter 7(2): 3-4.

Eagan, M. Kevin Jr., Sylvia Hurtado, Mitchell J. Chang, Gina A. Garcia, Felisha A. Herrera, and Juan C. Garibay. 2013. "Making a Difference in Science Education: The Impact of Undergraduate Research Programs." American Educational Research Journal 50: 683-713. doi: 10.3102/0002831213482038 
Economy, D. Ross, Julia L. Sharp, Julie P. Martin, and Marian S. Kennedy. 2014. "Factors Associated with Student Decision-Making for Participation in the Research Experiences for Undergraduates Program." International Journal of Engineering Education 30(6A): 1395-1404.

Hunter, Anne-Barrie, Timothy J. Weston, Sandra L. Laursen, and Heather Thiry. 2009. "URSSA: Evaluating Student Gains from Undergraduate Research in the Sciences." CUR Quarterly 29(3): 15-19.

Indiana University. Center for Postsecondary Research. About Carnegie Classification. 2015. Accessed November 5-21, 2015. http://carnegieclassifications.iu.edu/

Lopatto, David. 2004. "Survey of Undergraduate Research Experiences (SURE): First Findings." Cell Biology Education 3: 270-277. doi: 10.1187/cbe.04-07-0045

Lopatto, David. 2007. "Undergraduate Research Experiences Support Science Career Decisions and Active Learning." CBELife Science Education 6: 297-306. doi: 10.1187/cbe.07-06-0039

Lopatto, David. 2009. Science in Solution: The Impact of Undergraduate Research on Student Learning. Washington, DC: Council on Undergraduate Research. Tucson: Research Corporation for Science Advancement.

National Science Foundation (NSF). Program Evaluation Staff. 1990. NSF's Research Experiences for Undergraduates (REU) Program: An Assessment of the First Three Years. Washington, DC: Author.

Neckers, Douglas C. 1982. "The Threat to Undergraduate Research." Journal of Chemical Education 59: 328-329. doi: 10.1021/ed059p329

O'Connor, Sally E. 2014. Bio REU PI Workshop NSF Presentation. Accessed February 8, 2016. http://www.bioreu.org/downloads/2014_REU_PI_Mtg_OConnor.pdf

Russell, Susan H. 2006. Evaluation of NSF Support for Undergraduate Research Opportunities: Synthesis Report. Menlo Park, CA: SRI International. Accessed February 3, 2016. http://csted. sri.com/content/evaluation-nsf-support-undergraduate-researchopportunities-uro-synthesis-report

Russell, Susan H., Mary P. Hancock, and James McCullough. 2007. "Benefits of Undergraduate Research Experiences." Science 316: 548-549.
Schmitz, Heather Johnson, and Karen Havholm. 2015. "Undergraduate Research and Alumni: Perspectives on Learning Gains and Post-graduation Benefits." CUR Quarterly 35(3): $15-22$.

Seymour, Elaine, Anne-Barrie Hunter, Sandra L. Laursen, and Tracee DeAntoni. 2004. "Establishing the Benefits of Research Experiences for Undergraduates: First Findings from a ThreeYear Study." Science Education 88: 493-594. doi: 10.1002/ sce. 10131

Thiry, Heather, Timothy J. Weston, Sandra L. Laursen, and Anne-Barrie Hunter. 2012. "The Benefits of Multi-Year Research Experiences: Differences in Novice and Experienced Students' Reported Gains from Undergraduate Research." CBE-Life Sciences Education 11: 260-272. doi: 10.1187/ cbe.11-11-0098

U.S. Bureau of the Census. 2000. Accessed February 4, 2016. https://www.census.gov/population/www/cen2000/maps/respop. html

U.S. Department of Labor. Bureau of Labor Statistics. 2016. CPI Inflation Calculator. Accessed February 2, 2016. http://data.bls. gov/cgi-bin/cpicalc.pl

Yaffe, Kirsten, Carol Bender, and Lee Sechrest. 2014. "How Does Undergraduate Research Experience Impact Career Trajectories and Level of Career Satisfaction: A Comparative Survey." Journal of College Science Teaching 44(1): 25-33. doi: 10.2505/4/jcst14_044_01_25

\section{Christopher C. Barney}

Hope College, barney@hope.edu

Christopher C. Barney is the T. Elliot Weier Professor of Biology at Hope College, where he has been a member of the faculty for 36 years. He has served as the chair of the Biology Department and the faculty moderator at Hope and as a member of the Education Committee of the American Physiological Society. He also served as the PI or co-PI of seven NSF REU awards and as the director of Hope's HHMI program. He and the undergraduate students in his lab do research in the areas of thirst and water balance, as well as the regulation of metabolic rate, body temperature, and blood pressure. 